\title{
MAINTENANCE PRIORITY ASSOCIATED WITH POWERED TWO-WHEELER SAFETY
}

\author{
ANTONELLA RAGNOLI, MARIA VITTORIA CORAZZA, PAOLA DI MASCIO \& ANTONIO MUSSO \\ Department of Civil, Building and Environmental Engineering, "Sapienza" University of Rome, Italy
}

\begin{abstract}
Powered Two-Wheelers (PTWs) provide a suitable mode for a large portion of population in many cities due to rider's personal convenience and the vehicle supposed easiness of manoeuvring. At the same time PTWs present serious safety issues compared to other motorized vehicles. This paper reports the main outcome of study carried out in Rome, where this mode is very popular and assesses the economic efforts to make infrastructure safer for PTWs. The methodology, extensively described in the paper, includes three steps: the accident analysis, the development of economic indicators of accidents costs, the maintenance priority. In the first step, the location of the PTWs local accidents are identified, then the accidents are analysed by means of the suitable indicators and, among these the Safety Potential - SAPO. Lastly, according to the results of the analysed indicators the need of infrastructure maintenance will be defined. As usually, SAPO is applied to rural areas, it has been adapted to describe the phenomena of the urban area in hand. As a result, the estimation of the saving potential to improve the infrastructure safety levels, thus reducing the amount of accidents, is presented, along with recommendations on how to upscale the SAPO at city level.
\end{abstract}

Keywords: safety, accident costs, Powered Two-Wheelers, maintenance.

\section{INTRODUCTION}

As a mode of urban transportation, Powered Two-Wheelers (PTWs), i.e. motorcycles, mopeds and scooters, encompass a great variety of vehicles and they are used for a wide range of purposes. Although stricter safety measures for riders have been progressively enforced through the years, PTWs accidents rates are still high worldwide.

According to the 2015 WHO Road Safety Report data [1], the dominance of the mode and the poor compliance to safety requirements contribute in many cases to a high fatality rate. But high PTWs ownership rates, poor enforcement of regulations and controls are significant but not exhaustive explanations to that and for a long time in scientific and grey literature emphasis was also placed on low income levels as additional contributing factors: "Road accidents disproportionately affect the poor, making road safety an economic development imperative. Most of the victims of road accidents aren't even in a motor vehicle. Pedestrians, cyclists and motorcycle riders are the most vulnerable road users and account for the majority of traffic deaths in low and middle income countries" [2].

But in Europe, where PTWs are not the dominant mode, reasons for the accidents national rates must be searched elsewhere. ERSO statistics and others [3], [4], confirms that PTWs motorization rates are higher in the southern areas, as reported in Table 1, where Greece, with 128 mopeds and 142 motorcycles per 1,000 inhabitants, is ranked first. But the very high ownership rates of motorcycles in Switzerland, Germany and Austria or of mopeds in Finland seem to debunk the myth of milder climate as a contributing factor to the PTWs usage.

Table 1 also highlights that the fatality rate generally decreased in the last decade; on the one hand, the progressive enforcement of stricter regulations and controls can be credited for this. But on the other hand, the 2011-2012 overall economic downturn has decreased the sale, and consequently, the fleet of PTW across Europe [5], thus contributing to reduce the role of the mode in the mobility patterns. 
Table 1: PTWs fatalities rates in selected European countries, year 2015 [1], [3].

\begin{tabular}{|c|c|c|c|c|c|c|c|}
\hline \multirow[t]{2}{*}{ Country } & \multicolumn{2}{|c|}{$\begin{array}{l}\text { PTWs Motorization } \\
\text { rate per } 1,000 \text { inh. } \\
\text { (units) }\end{array}$} & \multicolumn{2}{|c|}{$\begin{array}{l}\text { Helmet wearing } \\
\text { rate }(\%)\end{array}$} & \multirow{2}{*}{$\begin{array}{l}\mathrm{R}_{\mathrm{d}} \\
(\%) \\
* *\end{array}$} & \multicolumn{2}{|c|}{$\begin{array}{l}\text { Fatality rate of } \\
\text { PTWs riders } \\
\text { (event } / 10^{6} \text { inh.) }\end{array}$} \\
\hline & Moped & Motorcycle & Driv. & Pass. & & 2005 & 2014 \\
\hline Austria & 35 & 53 & \multicolumn{2}{|c|}{$>95$ all riders } & 22 & 16.9 & 10.8 \\
\hline Belgium & n.a. & 41 & 99 & 99 & 16 & 14.6 & 9.1 \\
\hline Czech Rep.* & 46 & 47 & 95 & 85 & 11 & 12.2 & 9.1 \\
\hline Finland & 57 & 47 & n.a & n.a & 11 & 6.9 & 3.7 \\
\hline France & 17 & 48 & 98 & 92 & 24 & 20.5 & 12.7 \\
\hline Germany & 25 & 50 & 99 & 99 & 19 & 11.9 & 8.3 \\
\hline Greece & $128 *$ & $142 *$ & 75 & 46 & 32 & 41.7 & 27.3 \\
\hline Hungary & n.a. & $15^{*}$ & n.a & n.a. & 14 & 26.9 & 13 \\
\hline Iceland & 9 & 25 & n.a & n.a. & 6 & 3.4 & 0.0 \\
\hline Italy & 36 & 109 & \multicolumn{2}{|c|}{90 all riders } & 26 & 26.0 & 13.4 \\
\hline Luxembourg & 16 & 31 & n.a. & n.a. & 18 & 13.0 & 14.6 \\
\hline Netherlands & 30 & 39 & $94-100$ & 84 & 13 & 8.2 & 4.9 \\
\hline Norway & $35^{*}$ & $47 *$ & 99 & 99 & 13 & 7.6 & 4.3 \\
\hline Poland & 32 & 31 & \multicolumn{2}{|c|}{97 all riders } & 9 & 5.5 & 8.1 \\
\hline Slovenia & 20 & 24 & n.a. & n.a. & 17 & 19.0 & $10.2^{*}$ \\
\hline Spain & 44 & 64 & 99 & 99 & 21 & 18.1 & 7.3 \\
\hline Switzerland & 22 & 86 & \multicolumn{2}{|c|}{$96-100$ all riders } & 20 & 12.4 & 6.6 \\
\hline Sweden & 11 & 32 & $90-97$ & $90-97$ & 17 & 6.0 & 4.0 \\
\hline UK & 1 & 18 & n.a. & n.a. & 19 & 10.0 & 5.5 \\
\hline
\end{tabular}

Nevertheless, road accidents still take a significant toll on lives every year in Europe, PTW fatalities accounting for $18 \%$ of the total number of road deaths in the EU-28 countries in 2013 [6], among them, 15\% come from motorcycles and 3\% to mopeds fatal crashes. In the same year, if compared to passenger's cars, per 100,000 registered vehicles, the fatalities consisted in respectively 11 deceased motorcyclists versus 5 deceased car occupants [6]. To be noted that motorcycling is the mode of transport for which the number of fatalities decreased least between 2005-2014 [7], as reported in Fig. 1.

Although between 2005-2015 a significant reduction occurred in the PTWs fatality rates in Italy [7], the phenomenon is still far from being negligible (52,920 events in 2014). Highest occurrence is recorded in some of the most populated regions in northern and central Italy, Tuscany, Latium (where Rome is located), Lombardy and Liguria, but fatality rates in percentage are below the national threshold (29.9\% of all events). On the contrary, higher fatality rates are equally recorded in northern (Piedmont, Veneto Trentino Alto and Adige, the latter with the highest record: $41 \%$ of all the events) and southern regions (Campania and Apulia) [8]. 


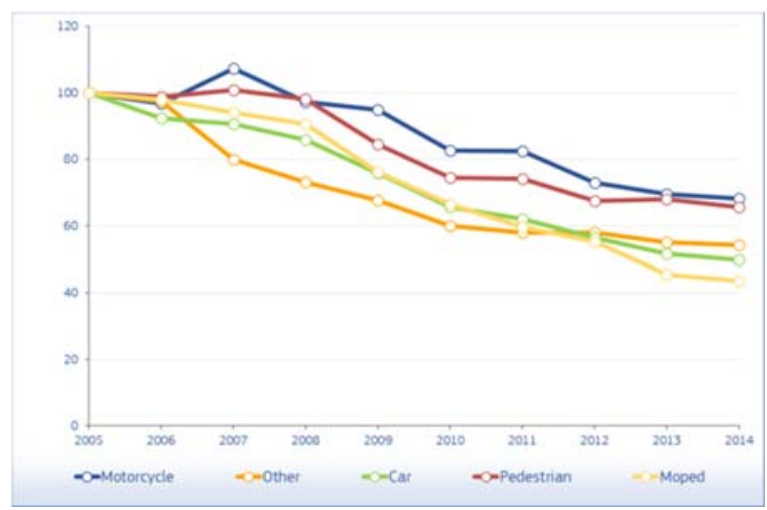

Figure 1: Index $(2005=100)$ of motorcycle and moped fatalities compared with other modes of transport in the EU member states, 2005-2014 [7].

\section{THE ROME CONTEMPORARY SITUATION}

In Italy, PTWs accidents take place mostly in urban areas and Rome is no exception. In this city, the estimated number of two-wheelers is about one for every five inhabitants [9]. PTWs are part of the mobility of everyday life: more than half of the overall number of trips by motorized two-wheelers occurs in a distance range between $2-11 \mathrm{~km}$ (just as for passenger's cars), and even for walking distances (0 to $1 \mathrm{~km})$ the use of PTWs is still an option [10]. This, the high local PTWs number of accidents (Fig. 2) and the high fatality rate (Fig. 3), highlight the importance of appropriate strategies to achieve safer mobility patterns. A focus on accidents occurred between 2010-2012 highlighted that the amount of injured and deceased riders is virtually equal to that of drivers, respectively $42.2 \%$ and $43.8 \%$ and differences in the locations of accidents can be detected. The central areas and namely the 1 st and the 2 nd Districts are those where the majority of PTWs accidents occur, as evidenced by the accident density referred to area (Fig. 4, left) and population (Fig. 4, right) of each district.

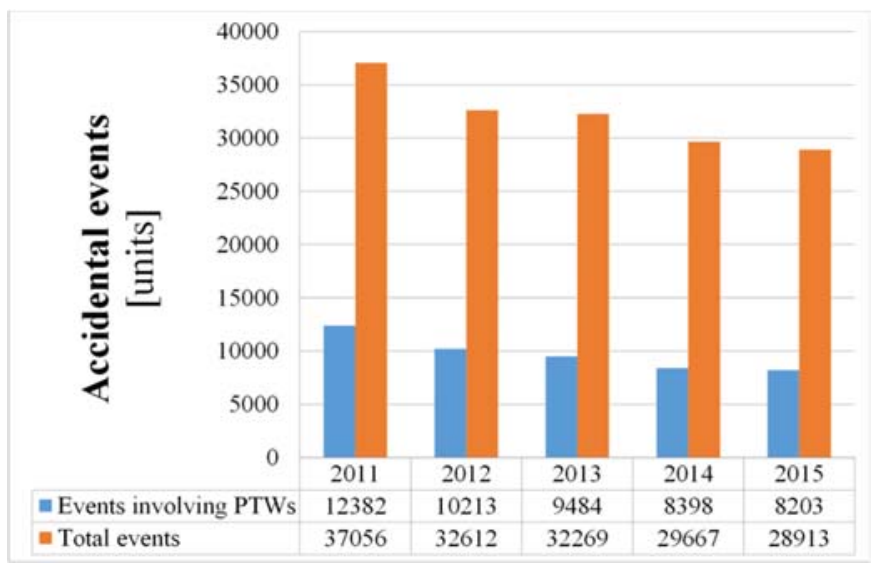

Figure 2: Total number of accidents and the number of PTW's accidents occurred between 2011 and 2015 in Rome [11]. 


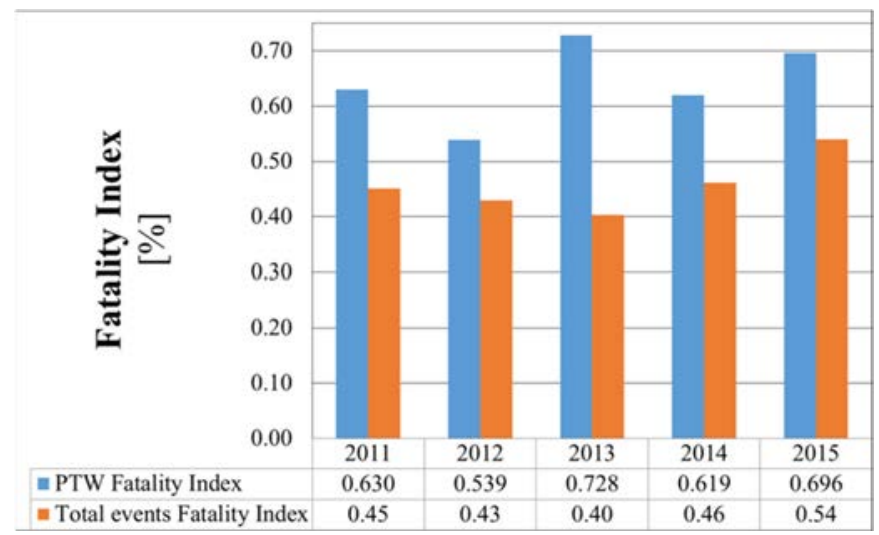

Figure 3: Accidents fatality rate for PTW and the other vehicles [11].
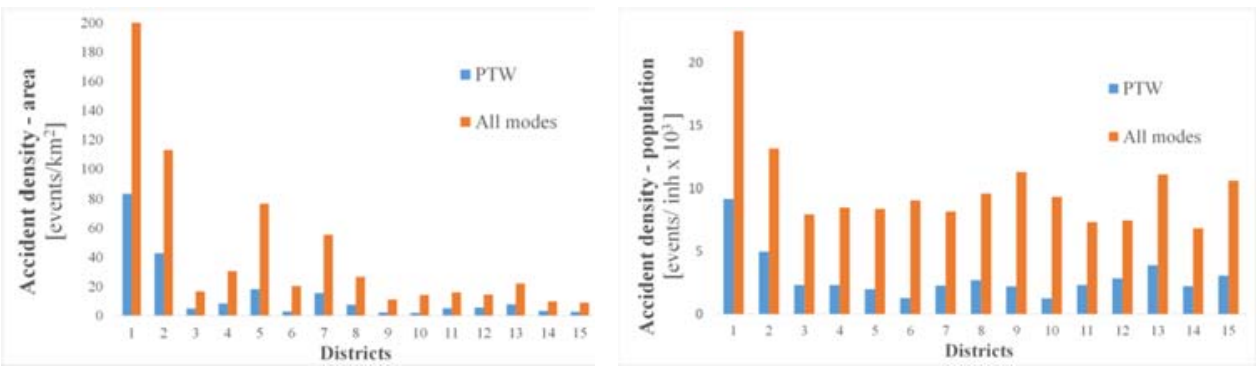

Figure 4: PTW accidents density per district population (left) and area (right) in Rome, 2015.

The two districts are rather different. The 1st District coincides with the city center: a compact setting and unique historic built environment with world-wide famous landmarks and very mixed land use; the area is in part daytimes and night times access-restricted to passenger cars (the so-called Limited Traffic Zone - LTZ), but not to PTWs, and in part pedestrianized.

The 2nd District represents a typical Roman medium-to-high income, high density area, where residential and business activities prevail. The built environment is also high, mostly with low-rise buildings (five stories in average), planted strips and plenty of vegetation, full provision of sidewalks, which make them ideal for walking.

Both districts can be considered valid test fields to analyze PTWs accident trends. A preliminary study on PTWs accidents phenomena was focused on the 1st District [12], but its built environment premium value and sensitive features and the extended LTZ regulation enforced for passenger cars only led to conclusions just partly transferable to the other areas of the city, and in general to other urban areas across Europe where the PTWs role is not negligible.

This is the reason why, the current study was focused on the 2nd District, more similar to many urban districts in Europe, and therefore more generally applicable for the analysis of the PTWs accidents phenomena. The study on a 2nd District main collector, Via Salaria, reported in the next sections serves, as a case in point for assessing recurring problems of 
main urban roads with large traffic flows, in spite of their modest capacity (usually due to restricted sections due to the built environment constraints).

\section{THE METHODOLOGICAL APPROACH}

Scientific and grey literature provide a wide array of methods and indicators to assess road safety ([13]-[17] just to mention a few of the most cited references), but virtually all of them have been formulated with generic drivers' behaviours in mind, not PTW riders', or for general environments.

Recent studies for the Rome case [12], [18], assessed the possibility to "customize" the so-called Safety Potential or SAPO index, $\left(\mathrm{k} € / \mathrm{km}^{*}\right.$ year) to the PTWs events. SAPO was enforced by the Italian "Guidelines on road safety management" (as reported in the National Decree 2.5.2012), as a key indicator within the Network Safety Management (NSM) assessment procedure [19]. NSM provides a dedicated methodology to analyse existing road networks, with the aim to enable road administrations to determine road sections with a poor safety performance. In this frame, SAPO enables to draw a priority list of road links for which is of the utmost importance to intervene to improve safety, by assessing the consequent expected reduction of accidents and costs to these associated.

The Italian regulations also include the calculation of an additional indicator: The Accident Rate $A_{r},[20]$, and consequently this study included both SAPO and $A_{r}$ in the assessment of the safety levels along Via Salaria. This road is a typical example of an urban road performing not according to capacity, and thus resulting into an unsafe link in the local network; remarks on the applicability of the method are provided and eventually conclusions on the upscaling of results are drawn.

The analysis was performed considering accident data from 2011-2015 involving PTWs available at the Rome Municipality Open Data Project official databank [11], collected by the police and validated by the Italian Institute of Statistics. For each event, spatial location information and a set of standard alpha-numeric attributes are provided, in order to fully describe operational conditions and circumstances of each accident.

The availability of the spatial information for each accident enables to determine the position of each event along the road, which is represented by a graph, to highlight the relation between accident and road. The associated Geographic Information System (GIS) enabled to create a black spot map (Fig. 5), where PTWs accidents are identified and located and consequently road sections and links with high accident rates highlighted.

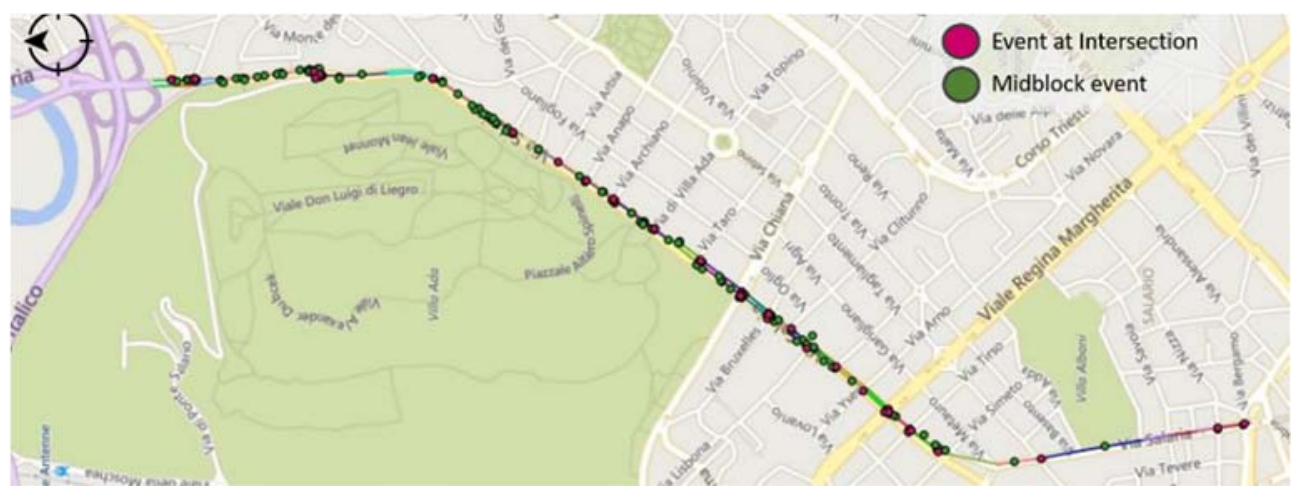

Figure 5: Via Salaria PWT black spot map. 


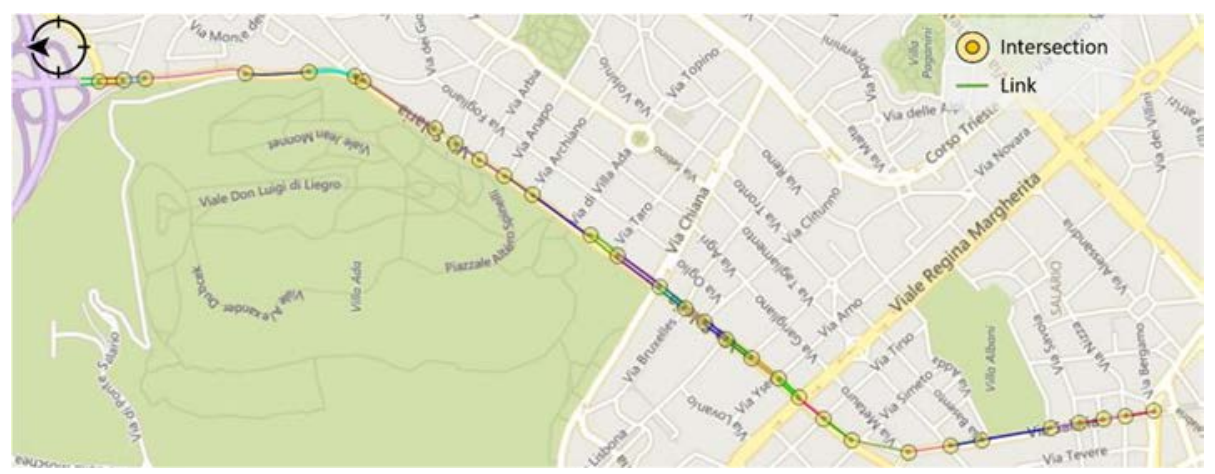

Figure 6: Via Salaria sections, with homogeneous characteristics.

GIS referencing univocally interrelates the event to the closest topological elements of the road graph (links or nodes), by means of an algorithm based on the nearest distance criteria, considering a buffer area of 15 meters from the road axis. The Via Salaria graph analysed was divided into sections, with homogeneous characteristics in term of geometrics features (amount of lanes, types of carriageway, location and amount of intersection) and traffic conditions (average daily traffic flows), as in Fig. 6.

\subsection{The indicators selection}

In order to investigate the accident phenomena along Via Salaria, the above-mentioned indicators, the accident rate $A_{r}$, and the SAPO index, were calculated for each section and node.

$A_{r}($ event $/ \mathrm{veh} \mathrm{km})$ is defined as the number of events occurred on the road section $i$ during a given period (in years) $t$, per the total traffic flow and the road section length. $A_{r}$ can be calculated for each considered link as indicated in [20]:

where:

$$
A_{r}=\frac{10^{6} \cdot N_{i}}{365 \cdot l_{i} \cdot \sum_{t} A D T T_{i, t}}
$$

$N_{i}$ is the amount of events (units)

$l_{i}$ is the road section length $(\mathrm{km})$

$A D T_{i, t}$ is the Average Daily Traffic flow.

Similarly, the accident rate $A_{r}$ at nodes, i.e. at intersections, can be calculated as:

$$
A_{\mathrm{r}}=\frac{10^{6} \cdot \mathrm{N}_{\mathrm{i}}}{365 \cdot \frac{1}{2} \sum_{\mathrm{t}} \sum_{\mathrm{j}} \mathrm{ADT}_{(\mathrm{i}, \mathrm{j}), \mathrm{t}}}
$$

In order to classify the road according to $A_{r}$, the Italian regulations [20]: define two threshold values $\mathrm{A}_{\text {up }}$ and $\mathrm{A}_{\text {low }}$, respectively for the upper and lower limits:

$$
A_{\text {low }}=A_{a}-K \cdot \sqrt{\frac{A_{a}}{M_{i}}}-\frac{1}{2 \cdot M_{i}}
$$

$$
A_{u p}=A_{a}+K \cdot \sqrt{\frac{A_{a}}{M_{i}}}+\frac{1}{2 \cdot M_{i}}
$$

with $A_{a}$ being the Average Accident Rate. 


$$
A_{a}=\frac{10^{6} \cdot \sum N_{i}}{365 \cdot \sum_{i} \sum_{t} l_{i} A D T_{i, t}}
$$

and

$$
M_{i}=365 \cdot l_{i} \cdot \sum_{i} A D T_{i, t}(\mathrm{veh} / 24 \mathrm{~h}) .
$$

$l_{i}$ being the road section length $(\mathrm{km})$

$\mathrm{K}$ being a constant of the Poisson Distribution $(\mathrm{K}=1.645$ with a error probability of $10 \%)$.

Considering these thresholds, each link and each intersection can be classified as:

- low accident rate if $\mathrm{A}_{\mathrm{r}}<\mathrm{A}_{\text {low }}$

- medium accident rate if $\mathrm{A}_{\text {low }}<\mathrm{A}_{\mathrm{r}}<\mathrm{A}_{\text {up }}$

- high accident rate if $\mathrm{A}_{\mathrm{r}}>\mathrm{A}_{\text {up }}$

In Fig. 7, the links and the intersections of Via Salaria with a low accident rate are highlighted in green, those with a medium accident rate in yellow and those with a high accident rate in red.

The SAPO index [19], is defined as the accident costs per kilometer of road length (cost density) that could be reduced if a road section would be designed according to accident prevention best practice. The higher the SAPO, the more societal benefits can be expected from improvements on road safety [21].

SAPO can be calculated as:

$$
S A P O=A C D-B A C D
$$

where, $A C D$ is the average density of accident cost related to the road section or intersection per length, as:

$$
A C D=A A C / L
$$

with $L$ being the road section length in $\mathrm{km}$,

$A A C$ being the average annual cost of accident, calculated as the product of number of injuries and fatalities occurred on the road section and the related cost, according to the Italian guidelines to assess social costs related to road accidents [22].

BACD is the Basis Accident Cost Density and represents the expected average annual amount of road accidents per kilometer and per severity levels. It is calculated as:

$$
B A C D=\frac{B A C R \cdot A D T \cdot 365}{10^{6}},
$$

where BACR is the Basis Accident Cost Rate which defines different costs for accidents occurred in different types of roads, and related to different types of road users, in this instance the. riders in the Via Salaria case study.

Sections eligible for the SAPO calculation were those with at least the occurrence of one event per year. The calculation of SAPO required in this case an adaptation process, being this index designed for general assessment. For example, an initial difficulty in calculating SAPO was to adapt its parameters to the urban context, as SAPO was initially designed to be applied to the Trans-European road Network - TEN according to the European Directive 2008/96 EC, and further recommended for wider applications, including the urban network. 


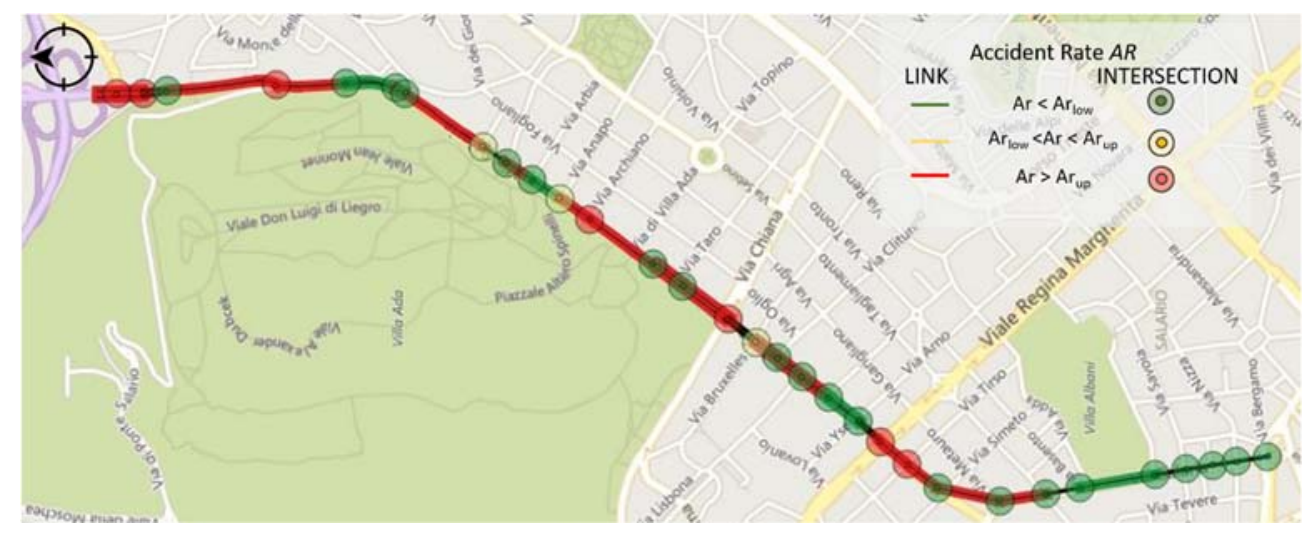

Figure 7: Classification of links and intersections on Via Salaria according to $A_{r}$.

A typical example in translating the application to urban areas, was the difficulty in assessing the appropriate length of road sections: the Italian guidelines recommend $100 \mathrm{~m}$ as a minimum, which is appropriate in non-urban environment, but hardly applicable in compact and consolidated city areas. In this case the topographical features of the Via Salaria area suggested to set for this parameter a minimum value of $40 \mathrm{~m}$. Similarly, an adaptation of the BACR parameter was necessary. The accident cost rates in the Italian scientific literature are defined mostly for passenger cars, motorways and rural roads, therefore far from being applicable to Via Salaria. As a reference, a value provided for a comprehensive study on traffic external costs in the Flemish Region [23], seemed the most suitable for the Via Salaria case and therefore used. This study enabled to estimate a cost equal to 400 Euros for each single event occurring on urban roads and involving PTWs.

According to all of the above, SAPO was calculated for the identified sections, which were ranked using a quantile distribution according to a three-class criterion reported in Fig. 8. This proved to be the most suitable for a comparison with $A_{r}$, because it enabled to highlight an average value, comparable to $\mathrm{A}_{\mathrm{a}}$.

Intersections were assessed through the average annual cost of accident - AAC (in Euro/1000*year) calculated as the product of number of injuries and fatalities occurred on the road section and the related base cost, according to the Italian guidelines to assess social costs related to road accidents [19], [22]. Also in this case the accident phenomenon was analysed using a quantile distribution on three classes, in order to provide a priority ranking of interventions based on the expected cost/benefit ratio for each intersection considered.

\section{RESULTS}

Considering the resulting distribution and the priority ranking of interventions based on the SAPO application, road segments characterized by the highest potential in terms of accident reduction are included in the third tercile.

The analysis shows that the SAPO is more sensitive to the amount of events occurred in the shorter segments. This is the reason why the selection of an appropriate range for the $\mathrm{L}$ parameter is of the utmost importance: in this study, the reference value of $40 \mathrm{~m}$ proved to be highly suitable to correctly evaluate the accident phenomena in an urban, compact environment. 
Figs 8 and 9 show respectively the results of SAPO and $A_{r}$ calculated in all the sections of Via Salaria. It is to be noted that the links with the highest SAPO values do not coincide with those with the highest $A_{r}$ values. In fact, the two indexes, although complementing each other, provide two different information: $A_{r}$ represents the actual accidental phenomena while SAPO represents the prospective benefits coming from a risk mitigation intervention. Fig. 10 shows the scenario resulting from the simultaneous overlap of SAPO and $\mathrm{A}_{\mathrm{r}}$ assessment on Via Salaria, and finally Fig. 11 shows the scenario for Via Salaria also including the rates the intersections are provided with. To prioritize interventions, the combination of SAPO (or AAC) and $A_{r}$ was thus considered, as reported in Fig. 12(a), by an Element Safety Ranking Matrix - ESRM. Highest importance is attached to SAPO outcomes because they provide information on the maximum achievable benefits. In the ESRM, elements with both indicators in the red field (as indicated in Fig. 10) are rated as "HIGH". Lower rates are considered when the SAPO codes are yellow or green. Within the same SAPO class, the intervention priority is set by $\mathrm{A}_{\mathrm{r}}$ level.

The SAPO assessment also provide directions for the mitigation interventions. These should be chosen also considering the mutual connection and the influence between adjacent links and intersections. Therefore, in order to consider the conditions of the adjacent elements, the Network Safety Ranking Matrix - NSRM reported in

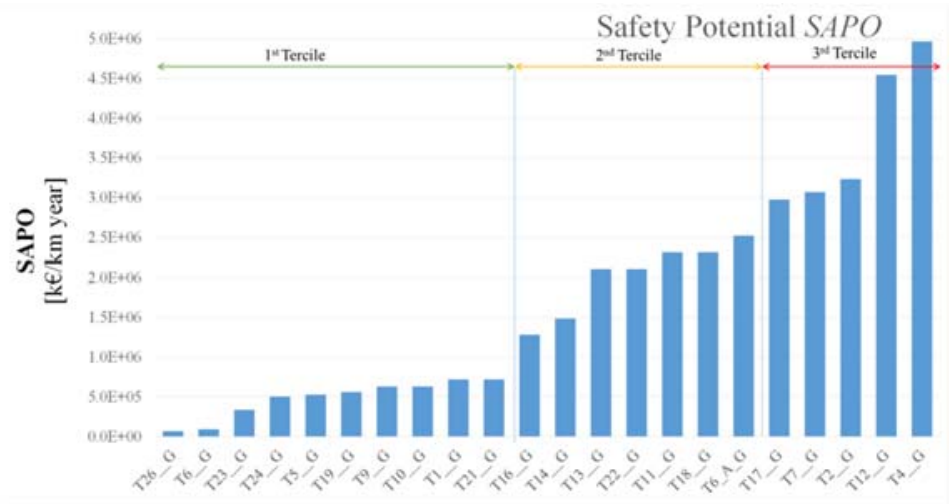

Figure 8: Classification of links on Via Salaria according to SAPO.

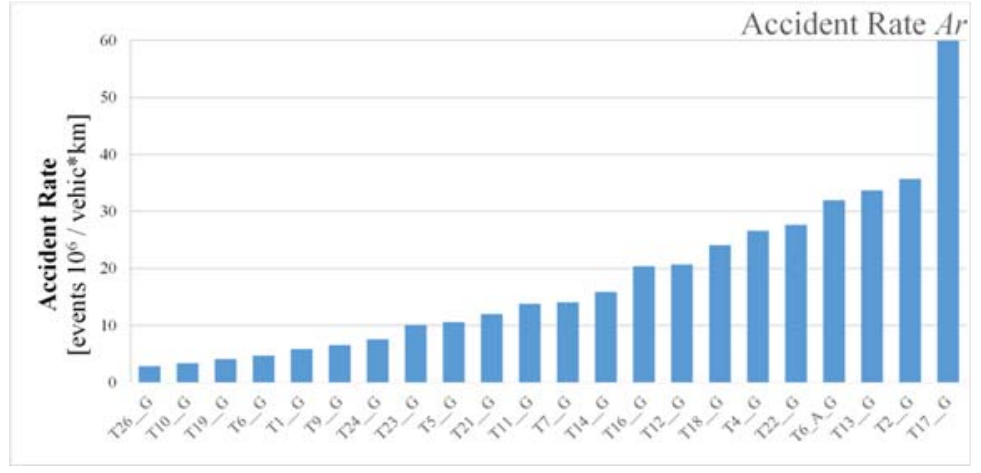

Figure 9: Classification of links on Via Salaria according to Ar. 
Fig. 12(b) was built. The NSRM resumes the significant combinations of links and nodes rating on the road. For each row, links and intersections highlighted in red are those with the highest values of SAPO or AAC, and the combination of at least two red-coded elements ranks as "high" the resulting sections of the road. Likewise, the links and intersections with the yellow codes are those where medium values of SAPO or AAC, and the combination of one or two red-coded elements results into assessing the rate "medium" to the composed sections of the road. The rate "moderate" is associated to sections with just one red element and the rate "low" for the sections with no red elements.

\section{CONCLUDING REMARKS}

SAPO enables to assess different road types, according to different traffic volumes at the same time and therefore contributes to improve accuracy in the analysis of black spots in general. More specifically, in this case it helped detect critical road sections and determine the range of how much could be saved thanks to appropriate interventions. In synergy with $\mathrm{A}_{\mathrm{r}}$ on the links and AAC at the intersections, it improves correctness of analysis.

Furthermore, the case of Via Salaria also suggests the possibility to achieve a reliable assessment of safety costs and extension of mitigating interventions, even when regulatory references are not updated or not comprehensive of specific modes. The case of Via Salaria stresses how parameters such as SAPO, if upscaled, might help understand the size of expenditure for the safety interventions at urban scale and where to intervene first.

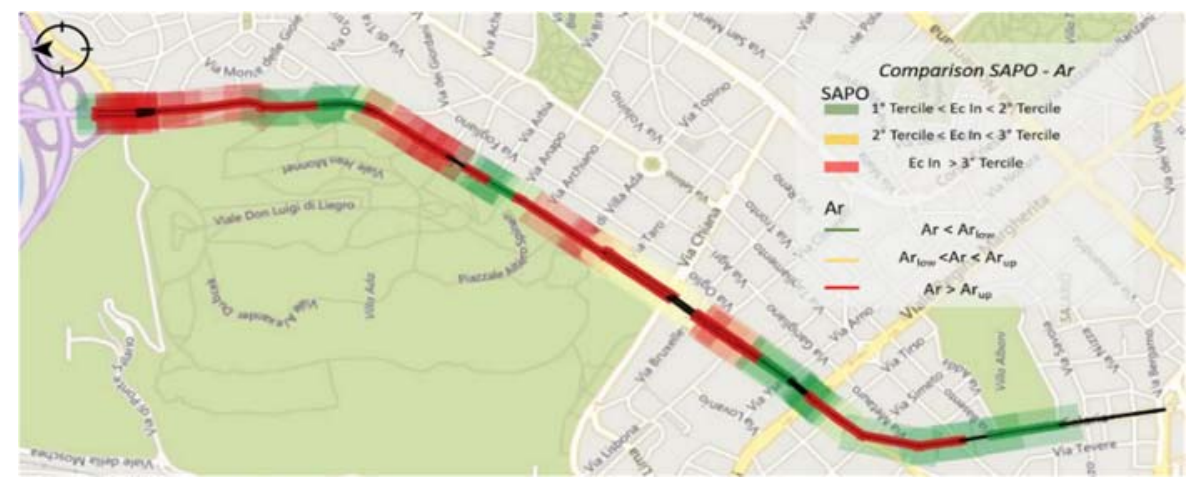

Figure 10: Comparison of SAPO and $\mathrm{A}_{\mathrm{r}}$ calculated on Via Salaria.

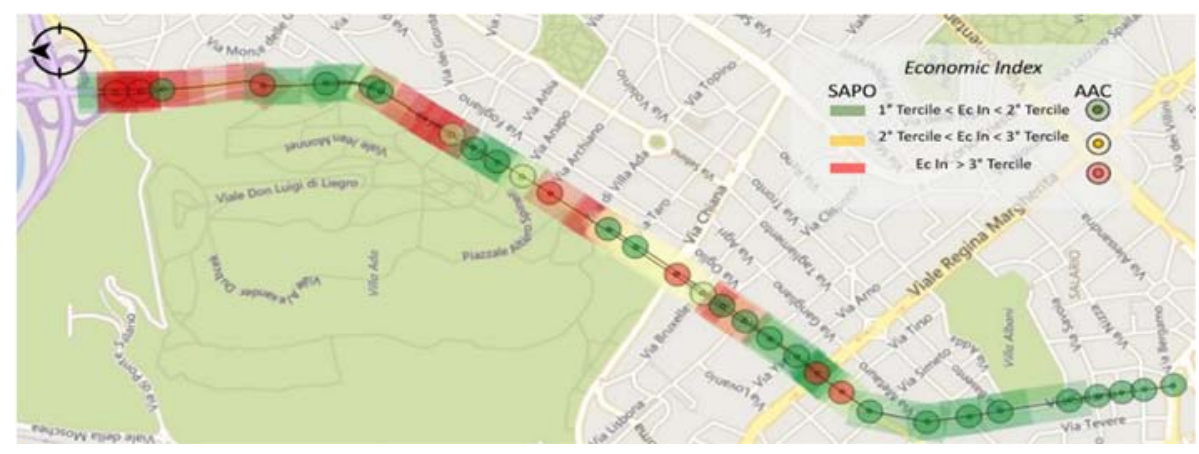

Figure 11: Rating of SAPO on Via Salaria links and AAC at intersections. 


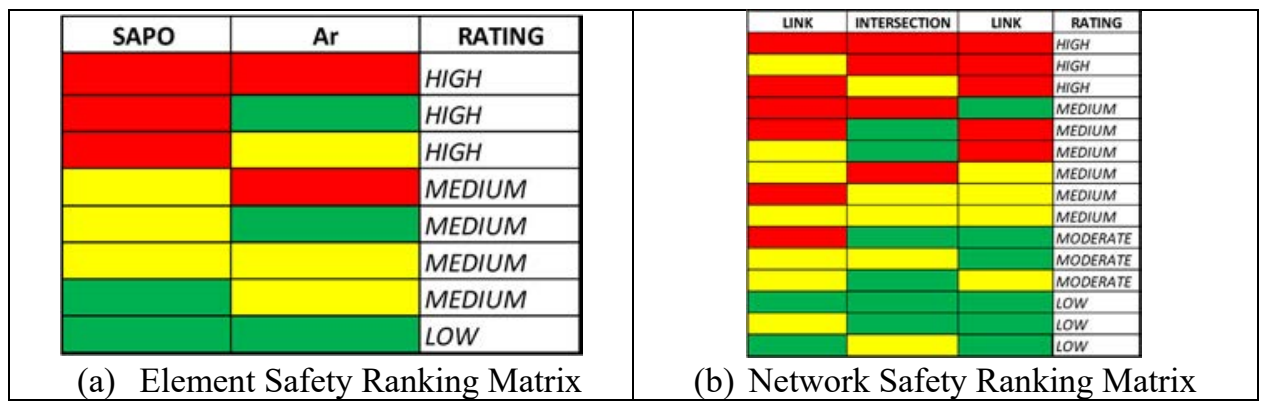

Figure 12: Safety Ranking Matrixes.

Moreover, should the results of the Via Salaria case be upscaled, consequences in terms for a whole reconsideration of PTWs in the city road safety policies will become unavoidable.

This lesson is also valid for all those communities where PTWs, although a dominant or relevant mode in the local modal share, are not properly involved in the local road safety agendas. Needless to say, additional efforts are required also to promote the research towards more specific studies in which parameters and procedures to evaluate PTWs safety conditions can be determined according to advanced analyses and tailored according to the riders' needs and not derived from general assessment procedures developed for passenger cars.

\section{REFERENCES}

[1] World Health Organization. Global Status Report on Road Safety 2015. Online http://www.who.int/violence_injury_prevention/road_safety_status/2015/en/, Accessed on: 10 Apr. 2017.

[2] World Bank (2009), Road Safety: A Development Challenge for South Asia. Online http://web.worldbank.org/WBSITE/EXTERNAL/COUNTRIES/SOUTHASIAEXT/0 ,contentMDK:20674828 pagePK:146736 piPK:146830 theSitePK:223547,00.html, Accessed on: 10 Apr. 2017.

[3] ERSO European Commission, Power Two Wheelers 2015, European Commission, Directorate General for Transport, 2015, Online. https://ec.europa.eu/transport/road safety/sites/roadsafety/files/ersosynthesis2015-ptw25_en.pdf, Accessed on: 10 Apr. 2017.

[4] Musso, A. \& Corazza, M.V., Motorized two-wheelers: contrasting aspect recurring problems and solutions for more comprehensive urban transportation policies, in Proceedings of 12th WCTR Congress, Lisbon 2010, Online http://www.wctrssociety.com/wp/wp-content/uploads/abstracts/lisbon/selected/01230.pdf, Accessed on: 10 Apr. 2017.

[5] International Transport Forum, Improving Road Safety for Motorcycles, Scooter and Moped Riders, OECD, Paris 2015.

[6] European Commission, Traffic Safety Basic Facts on Motorcycles and Mopeds, Directorate General for Transport, Jun. 2015. Online https:/ec.europa.eu/transport/ road_safety/sites/roadsafety/files/pdf/statistics/dacota/bfs2015_motomoped.pdf, Accessed on: 10 Apr. 2017.

[7] European Commission, Traffic Safety Basic Facts on Motorcycles and Mopeds, Directorate General for Transport, Jun. 2016. Online https://ec.europa.eu/transport/ 
road_safety/sites/roadsafety/files/pdf/statistics/dacota/bfs2016_motomoped.pdf, Accessed on: 10 Apr. 2017.

[8] Automobil Club Italia - ACI, Atlante della Sicurezza Stradale, Dati 2014, Online http://www.aci.it/fileadmin/documenti/studi_e_ricerche/dati_statistiche/atlante2014/ mobile/index.html\#p=1, Accessed on: 10 Apr. 2017.

[9] Rome Municipality, 2009. Piano Strategico della Mobilità Sostenibile 2009. Online www.psms.roma.it/, Accessed on: 2 Mar. 2014.

[10] ATAC (2006). Rapporto sulla mobilità 2005. Online http://www.atac.roma.it., Accessed on: 2 Mar. 2014.

[11] Rome Municipality, Il Progetto Open Data di Roma Capitale, Online https://dati.comune.roma.it/ Accessed on: 15 Dec. 2016.

[12] Corazza, M.V., Musso A., Finikopoulos K. \& Sgarra V., An analysis on health care costs due to accidents involving powered two wheelers to increase road safety, Transportation Research Procedia, 14(5), pp. 323-332, 2016.

[13] Compagne, J., MAIDS: Motorcycle Accidents In-Depth Study. ITF, Lillehammer, 2008.

[14] Elvik, R. et al. The Handbook of Road Safety Measures. Bingley, London, 2009.

[15] Hakkert, A.S. \& Gitelman, V., Road Safety Performance Indicators: Manual D3.8 of the EU FP6 project SafetyNet, 2007, Online, http://ec.europa.eu/transport/wcm/ road_safety/erso/safetynet/fixed/WP3/sn_wp3_d3p8_spi_manual.pdf, Accessed on: 2 Mar. 2014.

[16] Lamm, R. et al., Safety aspects of individual design elements and their interactions on two-lane highways: International perspective. Transportation Research Record: Journal of the Transportation Research Board, 1445, pp. 34-46, 1994.

[17] Morsink, P. et al., Development of footprint methodology for road safety. Transportation Research Record: Journal of the Transportation Research Board, pp. 104-112, 2007.

[18] Sgarra V., Di Mascio P., Corazza M.V. \& Musso A., An application of ITS devices for powered two-wheelers safety analysis: the Rome case study. In: Advances in Transportations Studies, 33(7), pp. 85-96, 2014.

[19] Ministero delle Infrastrutture e dei Trasporti. D.M. 2.5.2012. Linee Guida per la gestione della sicurezza delle infrastrutture stradali, Supplemento ordinario n. 182 alla Gazzetta Ufficiale, n. 209, 7.9.2012, Istituto Poligrafico dello Stato, Rome, 2012.

[20] Commissione di studio per le norme relative ai materiali stradali e progettazione, costruzione e manutenzione strade, D.P. CNR N. 13465 del 11/09/1995, Criteri per la classificazione della rete delle strade esistenti ai sensi dell'art. 13, comma 4 e 5 del nuovo codice della strada-Rapporto finale, CNR, Rome 1998.

[21] Nguyen, H.H., Taneerananon, P., Koren, C. \& Iamtrakul, P. Safety-potential-based black spot safety management approach: A case study in Ho Chi Minh City. Journal of the Eastern Asia Society for Transportation Studies, 10, pp 1991-2009, 2013.

[22] Ministero delle Infrastrutture e dei Trasporti, Studio di valutazione dei costi sociali dell'incidentalità stradale_Anno 2011. Online http://www.mit.gov.it/mit/ mop_ all.php?p_id=12919. Accessed on: 2 Mar. 2014.

[23] Delhaye E., De Ceuster G. \& Maerivoet S., Internalisering van externe kosten van transport in Vlaanderen, studie uitgevoerd in opdracht van de Vlaamse Milieumaatschappij, MIRA, Transport \& Mobility, 2010 Leuven. Online http://www.milieurapport.be/Upload/main/0_onderzoeksrapporten/2012/MIRA_Exte rne_Kosten_Transport_TW.pdf, Accessed on: 10 Jan. 2017. 